\title{
VOTO ESTRATÉGICO E COORDENAÇÃO ELEITORAL Testando a Lei de Duverger no Brasil
}

\section{Fernando Guarnieri}

Universidade do Estado do Rio de Janeiro (UERJ), Rio de Janeiro - RJ, Brasil. E-mail: fhguarnieri@gmail.com

DOI: http//dx.doi.org/10.17666/308977-92/2015

\section{Introdução}

Em 1951 foi publicado Les partis politiques de Maurice Duverger, um dos livros de maior impacto na ciência política. Naquele livro, Duverger formula a proposição que leva seu nome, a famosa Lei de Duverger. Como poucas são as proposições de politólogos que adquirem o status de lei, ainda que contestadas por alguns, as de Duverger foram exaustivamente testadas nos mais diferentes contextos. No entanto, surpreendentemente, no Brasil esse debate teve pequena repercussão, sobretudo no que tange às eleições majoritárias. ${ }^{1} \mathrm{O}$ presente artigo pretende contribuir para o preenchimento dessa lacuna.

A falta de estudos sistemáticos sobre o efeito das regras eleitorais no número de partidos deve-se ao fato de os estudos que investigam o sistema par-

Artigo recebido em 17/04/2015

Aprovado em 31/07/2015 tidário brasileiro instaurado a partir de 1980 terem privilegiado as eleiçôes parlamentares que ocorrem sob o sistema de representação proporcional (Lima Jr., 1997). Na representação proporcional, os custos de entrada nas disputas eleitorais são baixos e, portanto, os mecanismos clássicos identificados pela literatura para reduzir o número de partidos não operam. Elites políticas e eleitores não teriam por que coordenar suas estratégias/votos.

As eleiçôes majoritárias, ao contrário, envolvem poucas cadeiras e têm custos de entrada elevados, o que, de acordo com a tese de Duverger, limitaria o número de partidos na disputa. O mecanismo pelo qual isso ocorre é captado pela Lei de Duverger. Durante mais de sessenta anos, as proposições de Duverger foram criticadas, estendidas e testadas por inúmeros pesquisadores em diversos países. Neste artigo, pretendemos testar essas proposições no que tange às eleiçōes majoritárias no Brasil. $\mathrm{O}$ intuito não é só verificar o efeito redutor do sistema eleitoral majoritário, mas 
também quanto esse efeito se deve à coordenação de elites vis-à-vis a coordenação dos eleitores.

Primeiramente, o artigo apresentará a Lei de Duverger e suas extensôes, mostrando como a fórmula de Gary Cox (1997) - de verificação do efeito dos sistemas majoritários no número de partidos pode ajudar a identificar o tipo de coordenação que leva à redução desse número. A seguir, a fórmula de Cox será aplicada para testar a Lei de Duverger nas eleições municipais, estaduais e federal.

\section{A Lei de Duverger e suas extensóes}

O modo convencional de se descrever um sistema partidário é a partir do número de partidos. A distinção básica é entre sistemas bipartidários e sistemas com mais de dois partidos (Duverger, 1970). Para Duverger, o bipartidarismo apresentava um caráter natural, pois as questóes políticas se apresentam sob forma dualista, mais ainda: "o movimento natural das sociedades orienta-se para o bipartidarismo, podendo, evidentemente, ser contrariado por tendências inversas" (Idem, p. 252). ${ }^{2}$

As tendências inversas que levam ao multipartidarismo seriam o "sinistrismo" e a sobreposição de dualismos. O "sinistrismo" se dá quando um partido de centro assume o governo e perde uma ala mais à esquerda contrariada com a moderação que o partido adota. Essa facção à esquerda forma um novo partido que, sendo bem-sucedido eleitoralmente, acaba por tomar medidas moderadas, perdendo também sua facção mais à esquerda. Isso aconteceria sucessivamente, gerando uma miríade de partidos.

A sobreposição de dualismos ocorre quando a política se dá em várias dimensões, surgindo várias dualidades nas quais diferentes partidos assumem suas posições. Assim, em países onde a questão religiosa tem grande importância, poderiam existir quatro partidos: dois posicionados nos extremos da dimensão econômica, de tipo conservador/liberal, e outros dois posicionados nos extremos da dimensão secular/religiosa.

Essa distinção entre dois e vários partidos e o caráter natural atribuído ao bipartidarismo permitiu que se associasse estabilidade democrática ao número de partidos. Conforme Mair:
Assim sistemas bipartidários, característicos do Reino Unido e dos Estados Unidos, e que, invariavelmente, envolviam governos unipartidários, deveriam levar a maior accountability, alteração no poder e competição moderada em torno do centro. Sistemas multipartidários, por outro lado, que geralmente requerem governos de coalizão, e que são característicos de países como França, Itália, impediam que os eleitores tivessem voz na formação de governo, não facilitava a alternância no poder e, algumas vezes, favoreciam confrontos ideológicos extremistas entre partidos políticos de base restrita (1997, p. 200, tradução do autor).

A partir dessa primeira distinção elaborada por Duverger, surgiram outras como a de Blondel que, além do número de partidos, levava em conta o tamanho relativo desses partidos. Blondel (1982) distingue quatro tipos de sistemas partidários: sistemas de dois partidos, sistemas de dois partidos e meio, sistemas multipartidários com um partido dominante e sistemas multipartidários sem partidos dominantes.

Stein Rokkan também estende o trabalho de Duverger e distingue categorias de multipartidarismo. Rokkan (1997) leva em conta a possibilidade da ocorrência de partidos majoritários (equivalente ao multipartidarismo de partido dominante de Blondel) e a fragmentação dos partidos minoritários. Esse autor distingue três tipos de sistemas partidários. O primeiro tipo é o sistema "britânico-germânico", no qual há a competição entre dois grandes partidos com um terceiro partido minoritário também presente na disputa. $\mathrm{O}$ segundo tipo é o "escandinavo", onde um partido grande disputa com uma aliança entre três ou quatro pequenos partidos. O terceiro tipo de sistema partidário é o sistema "equilibrado", onde três ou mais partidos de tamanho equivalente participam da disputa.

A tipologia mais influente é a de Giovanni Sartori (1982). Esse autor aperfeiçoa o modelo de Duverger fazendo uma distinção entre polaridade e polarização, isto é, entre o número de partidos e a distância ideológica entre os partidos. Esses dois critérios não seriam independentes e sistemas multipartidários tenderiam à maior polarização. Essa distinção permitiu a Sartori classificar os sistemas partidários em sistemas de dois partidos, sistemas com até cinco partidos moderados 


\section{Quadro 1 \\ Classificação dos Sistemas Partidários}

\begin{tabular}{|c|c|c|}
\hline Autor & Principal critério de classificação & Principais sistemas partidários identificados \\
\hline Duverger & Número de partidos & $\begin{array}{l}\text { Sistema de dois partidos } \\
\text { Sistemas multipartidários }\end{array}$ \\
\hline Blondel & $\begin{array}{l}\text { Número de partidos } \\
\text { Tamanho relativo dos partidos }\end{array}$ & $\begin{array}{l}\text { Sistema de dois partidos } \\
\text { Sistemas de dois partidos e meio } \\
\text { Sistemas multipartidários com um partido } \\
\text { dominante } \\
\text { Sistemas multipartidários sem partidos dominantes }\end{array}$ \\
\hline Rokkan & $\begin{array}{l}\text { Número de partidos } \\
\text { Possibilidade de um partido marjoritário } \\
\text { Distribuiçáo da força dos partidos minoritários }\end{array}$ & $\begin{array}{l}\text { "Britânico - Germânico" (1 x 1) + } 1 \\
\text { "Escandinavo" } 1 \text { x } 3 \text { ou } 4 \\
\text { "Equilibrado" }(1 \text { x } 1 \text { x } 1)+2 \text { ou } 3\end{array}$ \\
\hline Sartori & $\begin{array}{l}\text { Número de partidos } \\
\text { Distância ideológica }\end{array}$ & $\begin{array}{l}\text { Sistema de dois partidos } \\
\text { Pluralismo moderado } \\
\text { Pluralismo polarizado } \\
\text { Sistema de partidos dominantes }\end{array}$ \\
\hline
\end{tabular}

Fonte: Mair (1997, p. 202).

(pluralismo moderado), sistemas com seis ou mais partidos polarizados (pluralismo polarizado) e sistemas de partidos predominantes. ${ }^{3}$

O Quadro 1 resume essas diferentes classificaçôes dos sistemas partidários.

Dada a importância do número de partidos em um sistema, inúmeros autores se dedicaram a entender que fatores levam ao bipartidarismo ou às várias formas de multipartidarismo. Os principais fatores que influiriam no número de partidos seriam de natureza socioeconômica, ideológica e técnica. São os fatores técnicos que serão analisados por Duverger. Para ele, o bipartidarismo apresenta um caráter natural, isto é, as opções políticas se apresentariam sempre sob forma dualista, que se refletem ou não em organizações partidárias. A questão para Duverger é entender por que esse caráter natural se revela em países como Inglaterra e não em países como a França. A resposta estaria em um fator geral de ordem técnica: o sistema eleitoral.

A associação que Duverger faz dessas duas variáveis ficou conhecida como Lei de Duverger: "o escrutínio majoritário de um só turno tende ao du- alismo dos partidos" e, pelo contrário, "o escrutínio majoritário de dois turnos ou a representação proporcional tendem ao multipartidarismo" - o que será chamado por Riker (1986) de "a hipótese de Duverger".

A ação desses fatores é descrita por Duverger nos seguintes termos:

O mecanismo dessa ação é muito simples: por exemplo, uma circunscrição britânica onde os conservadores têm 35.000 votos, os trabalhistas 40.000 e os liberais 15.000. É claro que o sucesso trabalhista repousa inteiramente na presença do Partido Liberal; se este último retirar seu candidato, pode-se calcular que a maioria dos sufrágios atrás dele agrupados se transfira para o Conservador e que uma minoria se divida entre o trabalhista e a abstenção. Duas hipóteses podem então apresentar-se: ou o Partido Liberal entra em acordo com o Conservador para retirar seu candidato (mediante compensações eventuais em certas circunscriçôes) e o dualismo se restabelece por fusão ou 
por aliança muito próxima da fusão, ou o Partido Liberal obstina-se a marchar sozinho: os eleitores abandonam-no, progressivamente, e o dualismo se restabelecerá por eliminação (Duverger, 1970, p. 258).

O bipartidarismo surge, portanto, por fusão ou eliminação. No primeiro caso, a redução do número de partidos se dá pela coordenação entre os partidos, no segundo a redução se deve à coordenação dos eleitores. A eliminação de terceiros partidos por ação dos eleitores seria explicada por dois fatores: um fator "mecânico" e outro "psicológico". O fator mecânico está ligado à sub-representação dos terceiros partidos em sistemas majoritários de um só turno. $\mathrm{O}$ fator psicológico está ligado ao fato de os eleitores compreenderem que perderão seu voto se continuarem a dá-lo ao terceiro partido. A fusão ou aliança entre partidos se daria pela antecipação dos efeitos "mecânico" e "psicológico" por parte da direção partidária. Assim, o bipartidarismo seria o resultado das decisões dos dirigentes partidários ou das decisões dos eleitores diante das regras dadas pelo sistema eleitoral.

Após ser enunciada nesse trabalho pioneiro, a Lei de Duverger foi testada em inúmeros estudos e exceçôes foram listadas e apresentadas como contraprova da influência do sistema eleitoral no sistema partidário. Outros trabalhos analisaram menos as evidências empíricas, detendo-se mais na lógica do argumento de Duverger e na sua construção teórica.

O trabalho de William Riker (1986) faz uma síntese dos "testes" da Lei de Duverger e mostra como, tanto do ponto de vista empírico como do ponto de vista teórico, essa Lei precisaria sofrer algumas adaptações para manter sua validade.

Do ponto de vista empírico, os casos do Canadá e da Índia seriam exceções que levariam à necessidade de se incluir novas condições à Lei de Duverger. ${ }^{4}$ Além da regra da maioria, também seria necessário estabelecer como condição para o bipartidarismo a ausência de um terceiro partido no nível nacional que fosse ao mesmo tempo o segundo partido no nível local, e a ausência de um Condorcet winner, isto é, um partido dominante.

Do ponto de vista teórico, as críticas se dirigem à premissa da racionalidade por trás do efeito psicológico da Lei, principalmente ao voto sofistica- do, isto é, a deserção de um partido sem chance de vitória em favor de outro partido, menos preferido mas com maior chance. As evidências empíricas relatadas por Riker mostram que o voto sofisticado ocorre de fato e é algo comum, mas este comportamento não seria universal. Assim, para que a Lei tenha validade geral, é preciso incorporar a possibilidade de que alguns atores não sejam racionais, nos termos previstos pelo efeito psicológico, e votem sinceramente. Isso explicaria a ocorrência de terceiros partidos mesmo em sistemas que, conforme a Lei de Duverger, deveriam ter apenas dois partidos.

Segundo Sartori, a fraqueza da Lei de Duverger é de natureza lógica por afirmar que o sistema eleitoral majoritário de um só turno é condição necessária e suficiente para o bipartidarismo. Para Sartori, esse tipo de sistema é necessário mas não suficiente, pois ele se aplica no nível local, onde se dá a decisão do eleitor. Portanto, não explica o bipartidarismo no nível nacional, mas sim local. Para essa explicação será necessária a intervenção de outra condição necessária, o tipo de sistema partidário.

Dependendo do tipo de sistema partidário, o efeito do sistema eleitoral no número de partidos seria maior ou menor. Sartori distingue sistemas partidários fortes e fracos conforme a influência de fatores pessoais na decisão do eleitor. Sistemas partidários fortes seriam aqueles dominados por partidos de massa que possuem vínculos ideológicos com os eleitores. Sistemas partidários fracos seriam aqueles onde imperam os vínculos pessoais.

Sistemas eleitorais fortes (majoritário de um turno) combinados com sistemas partidários fortes têm um efeito redutor no número de partidos. Sistemas eleitorais fracos (representação proporcional ou majoritário de dois turnos) combinados com sistemas partidários fracos não têm influência sobre o número de partidos. Quando sistemas eleitorais fracos se combinam com sistemas partidários fortes também há redução de partidos, mas apenas no nível local. Quando sistemas eleitorais fracos se combinam com sistemas partidários fortes, pode haver redução no número de partidos; no entanto, essa redução se deveria apenas ao caráter do sistema partidário. O Quadro 2 tenta tornar mais claras essas relações. 


\section{Quadro 2}

\section{Influência dos Sistemas Eleitoral e Partidário no Número de Partidos}

\begin{tabular}{lll}
\hline \multirow{2}{*}{ Sistema Eleitoral } & \multicolumn{2}{c}{ Sistema Partidário } \\
\cline { 2 - 3 } Forte & Forte (estruturado) & Fraco (náo estruturado) \\
\hline Fraco & Efeito redutivo do sistema eleitoral & $\begin{array}{l}\text { Efeito bloqueador do sistema } \\
\text { partidário }\end{array}$ \\
\hline
\end{tabular}

Fonte: Sartori (1986).

Essas observações permitem a Sartori reformular a Lei de Duverger do seguinte modo:

1. Dada a estruturação sistêmica [sistema partidário forte] e a dispersão entre distritos (como condiçōes necessárias), sistemas majoritários simples causam (são condições suficientes de) formatos bipartidários.

1.1 Alternativamente, uma estrutura sistêmica particularmente forte é, sozinha, condição suficiente e necessária para causar um formato bipartidário.

2. Dada a estruturação sistêmica, mas sem dispersão entre distritos, sistemas de maioria simples causam (são condições suficientes) a eliminação de partidos minoritários, mas não elimina e, portanto, permite a existência de tantos partidos quanto os que conseguem a maioria simples de votos nos distritos.

3. Dada a estruturação sistêmica, a representação proporcional leva a um efeito redutor causado por (como condição suficiente) sua não-proporcionalidade, Assim quanto maior a impureza da $\mathrm{RP}$, maior o custo de entrada para os partidos pequenos e maior o efeito redutor; e, reciprocamente, quanto menor a impureza, mais fraco o efeito redutor.

3.1 Alternativamente, uma estruturação sistêmica particularmente forte é, sozinha, a condição necessária e suficiente para se manter qualquer formato partidário preexistente à introdução da RP.

4. Com baixa estruturação sistêmica e assumindo $\mathrm{RP}$ pura, isto é, um custo de entrada igual para todos, o número de partidos é livre para se tornar tão alto quanto a quota permitir (Sartori, 1986, p. 63-64, tradução do autor).

Com essa reformulação, Sartori dá conta das exceçôes à Lei de Duverger, como o caso da Índia, que seria um exemplo de sistema partidário não estruturado. Essas alteraçōes também permitem estender os efeitos redutores para sistemas que adotam a representação proporcional. Quando a representação proporcional é "impura” e o sistema partidário é estruturado, há redução do número de partidos devido à desproporcionalidade do sistema. ${ }^{5}$

Shugart e Carey (1992) ${ }^{6}$ dão sua contribuição ao debate ao estudar os efeitos da combinação de mais de um sistema eleitoral sobre o número de partidos. Mais especificamente, esses autores procuram entender os efeitos conjuntos das eleições presidenciais e legislativas em regimes presidenciais. As variáveis-chave no modelo interpretativo dos autores são as regras eleitorais (magnitude do distrito) e o ciclo eleitoral (o timing das eleições legislativas em relação às eleições presidenciais).

Conforme Shugart e Carey, eleições presidenciais majoritárias de turno único, quando simultâneas a eleições proporcionais, "contaminam" estas, isto é, atenuam sua tendência à proliferação de partidos, e são "contaminadas" por estas que atenuam o efeito redutor das regras majoritárias. Assim, teríamos mais partidos lançando candidatos a presidente do que a Lei de Duverger propóe e menos candidatos a cargos legislativos. ${ }^{7}$

Gary Cox irá se debruçar sobre a Lei de Duverger ao investigar os problemas de coordenação carac- 
terísticos da competição eleitoral. Cox (1997) está preocupado com as consequências da coordenação estratégica e com as características estruturais que determinam a natureza dos problemas de coordenação em diferentes sistemas políticos. Nessa perspectiva, a redução do número de partidos seria uma das consequências do processo de coordenação, sendo necessário explicar em que condiçôes e quais os mecanismos que fazem com que isso ocorra.

Para Cox, são três os fatores que determinam a natureza do problema de coordenação: as instituições eleitorais, as motivações políticas dos atores e as expectativas públicas (public expectations). Cox descreve a relação entre essas variáveis da seguinte forma:

Instituições eleitorais determinam como votos se traduzem em cadeiras. Se os atores políticos se preocupam principalmente em conquistar cadeiras na eleição em curso, então a influência das instituiçôes eleitorais no seu objetivo é direta. Se, mais ainda, os atores conseguem estimar com precisão as fatias de votos uns dos outros, então surge um jogo de coordenação bem estruturado no qual a perspectiva de uma coordenação bem sucedida é boa. Esse modelo corresponde à abordagem duvergeriana padrão às eleiçôes legislativas nos estudos eleitorais (1997, p. 8, tradução do autor).

Para Cox, o efeito redutor descrito por Duverger aparece toda vez que as "elites" políticas (líderes partidários, contribuintes, formadores de opinião etc.) conseguem se coordenar em torno dos candidatos com maior chance de vitória em um primeiro momento ou, caso falhem, os eleitores o façam em um segundo momento. Para Cox (1997, p. 30, grifo no original), "qualquer sistema eleitoral pode ser caracterizado por um limite superior de equilíbrio no número de candidatos (ou listas partidárias), de modo que se o número real exceder este limite há uma tendência para eleitores instrumentalmente racionais a concentrar em número menor".

Ao estabelecer que todo sistema eleitoral gera um upper bound no número de candidatos, Cox concorda com Sartori, o qual afirmava que a representação proporcional também estabeleceria um upper bound em maior ou menor grau conforme sua "pureza". Cox generaliza a Lei de Duverger e afirma que, em qualquer sistema eleitoral, o upper bound é dado pela fórmula $\mathrm{M}+1$, onde $\mathrm{M}$ é o número de cadeiras em jogo, ou seja, a magnitude do distrito.

Por traz dessa generalização está um modelo de comportamento do eleitor baseado na suposição de que este detém informação completa (quanto à expectativa pública e não quanto ao comportamento individual de cada eleitor) e age de maneira instrumental, ele irá procurar concentrar seu voto em candidatos viáveis, isto é, naquele candidato que estiver lutando pela última cadeira em jogo, pois é aí que seu voto fará diferença. Votar em um candidato que já está eleito (na expectativa dos eleitores) ou em outro que já está derrotado seria desperdiçar o voto.

Essas premissas comportamentais são utilizadas por Cox para construir seu modelo, quais sejam: 1) os eleitores têm preferências definidas e são instrumentalmente racionais no curto prazo, isto é, eles só se importam com o voto que pode influir no resultado da eleição corrente; 2) os eleitores têm informação incompleta quanto às preferências uns dos outros mas têm "crenças" sobre qual a distribuição dos votos; 3 ) as expectativas são racionais, isto é, a crença dos eleitores sobre quais candidatos são os mais fortes e quais são os mais fracos estão corretas; 4) os eleitores diante de suas preferências, crenças e expectativas procuram maximizar sua utilidade esperada votando na opção que lhe traga o maior benefício com maior probabilidade.

Esse modelo levaria a dois resultados: um seria uma situação de equilíbrio duvergeriano, onde o nível de voto estratégico é tão grande que o apoio a um terceiro partido desaparece completamente, no caso da plurality rule, ou se fixa no limite $\mathrm{M}+1$ nos outros casos. Outro resultado seria um equilíbrio não duvergeriano onde dois ou mais candidatos estão de tal forma empatados que fica impossível para o eleitor decidir qual tem maiores chances de vencer e, portanto, para qual se deve dar o voto estratégico. Neste último caso, não haveria redução no número de candidatos e todos estariam no mesmo patamar de votos.

A grande contribuição de Cox está no rigor, na formalização do modelo. A partir dessa formalização é possível especificar as condições em que a Lei de Duverger se aplica. A Lei só se aplica, novamente, se os eleitores forem instrumental- 
mente racionais e se importarem apenas com o resultado daquela eleição, descontando inteiramente o peso das eleiçôes futuras; se os eleitores tiverem acesso a informações públicas e corretas sobre a colocação dos candidatos; e se os eleitores se ajustarem uns ao comportamento dos outros. Esse ajuste levaria ao equilíbrio duvergeriano.

Dessa formulação Cox deriva um teste para verificar a presença ou não do voto estratégico no nível local, que batiza de teste de bimodalidade. A lógica do teste é simples: em um equilíbrio duvergeriano, a diferença entre os votos do primeiro candidato derrotado (o candidato na M+1a posição) e os votos do segundo candidato derrotado (na M+2a posição) é muito grande. Portanto, se dividirmos votos do segundo candidato derrotado pelos votos do primeiro candidato derrotado, o resultado seria muito pequeno, tendendo a 0 (zero). Já em um equilíbrio não duvergeriano, a diferença da votação do segundo candidato derrotado para o primeiro é mínima e a razão se aproximaria de 1 , já que não haveria voto estratégico. O nome do teste relaciona-se à forma esperada do gráfico quando se calcula essas razões para determinado número de eleiçôes: a maior parte dos casos estaria concentrada nas duas pontas do eixo $x$, formando picos nessas regiōes e um vale na região central.

Cox aplica o teste de bimodalidade nos casos de eleição majoritária em primeiro turno e nos casos de voto único não transferível (SNTV). Os casos analisados (Inglaterra, para o sistema majoritário uninominal - SMDP, do inglês Single Member District Plurality - e Japão, para SNTV) mostram que é possível identificar o voto estratégico em alguns casos, principalmente naqueles em que os distritos são mais competitivos.

Ao estender a análise do voto estratégico para sistemas de representação proporcional, Cox irá aprofundar os achados de Sartori, que afirmava haver voto estratégico também nesses sistemas. Cox irá generalizar a Lei de Duverger mostrando que esse voto estratégico leva a uma redução no número de candidatos, tendo a fórmula $\mathrm{M}+1$ como upper bound tanto para o sistema de sobras como para os sistemas de divisores. Cox também irá mostrar que, apesar disso, o efeito do voto estratégico não reduz necessariamente o número de listas, já que se pode desertar de um candidato bem colocado para outro na mesma lista, para garantir que esta saia vitoriosa. Por fim, Cox irá mostrar que o efeito do voto estratégico desaparece em distritos com magnitude maior que cinco.

\section{Lei de Duverger nas eleições majoritárias}

Nesta seção, buscaremos evidências que sustentem ou não a análise de Cox no caso brasileiro, para assim verificar se há indícios de voto estratégico no país. O Brasil é um excelente laboratório para testar essa teoria, já que nele coexistem os sistemas de voto majoritário de um turno, majoritário de dois turnos, e representação proporcional. As cidades com menos de 200 mil habitantes e os estados na eleição para senador adotam o primeiro sistema; as cidades com mais de 200 mil habitantes, os estados nas eleições para governador e a União, nas eleições para presidente, adotam o segundo; as eleições para as câmaras de vereadores, deputado estadual e deputado federal adotam a representação proporcional.

Vamos nos concentrar, neste artigo, nas eleições majoritárias, diferenciando eleições sob sistema majoritário de um turno e eleições sob sistema majoritário de dois turnos. Para analisar os efeitos do sistema majoritário de um turno no número de candidatos, buscaremos evidências de voto estratégico nos municípios com menos de 200 mil habitantes. Para testar os efeitos redutores do sistema de dois turnos, serão analisadas as eleições para governador do estado.

\section{Lei de Duverger nas eleiçóes para prefeito}

Para testar os efeitos das eleiçôes majoritárias de um turno no número de partidos, examinaremos as eleições para prefeito em municípios brasileiros que tinham entre 10 mil e 200 mil habitantes ${ }^{8}$ nas eleições de 1996 a 2012. No total, foram analisadas 13.476 eleições. O Gráfico 1 mostra a distribuição do número de candidatos na disputa por eleição. $\mathrm{O}$ primeiro aspecto que chama a atenção é o grande número de disputas entre apenas dois candidatos 5.587 ou $41,4 \%$ do total. Também se destaca o fato de que, em $66 \%$ das eleições, concorreram três ou menos candidatos, e mais de $85 \%$ delas tinham menos que quatro candidatos. 


\section{Gráfico 1 \\ Distribuição das Eleições Municipais Conforme o Número de Candidatos em Disputa}

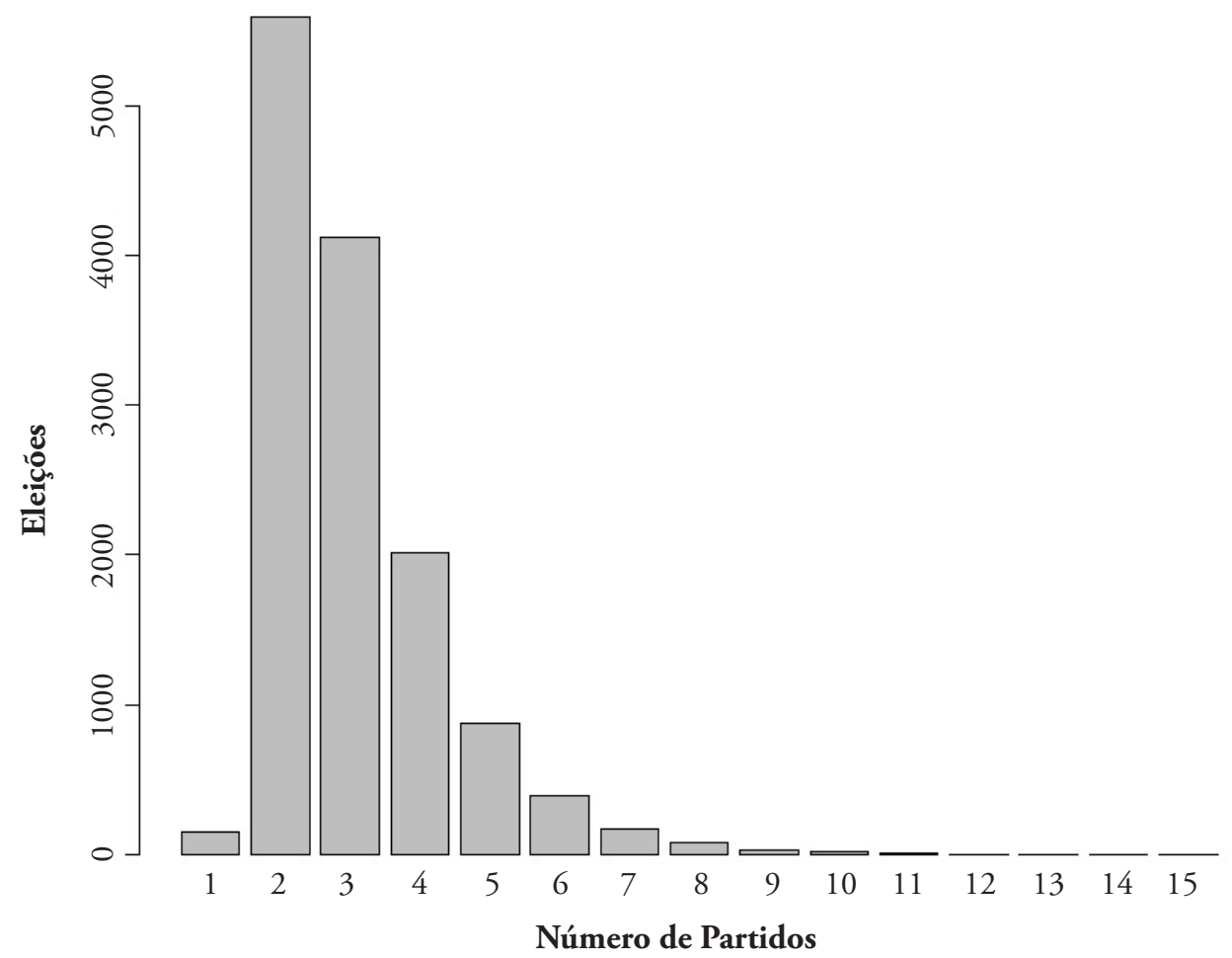

Fonte: elaboração própria a partir de dados do TSE. Disponível em http://www.tse.jus.br/eleicoes/eleicoes-anteriores/ eleicoes-anteriores, consultado em 9 set. 2015.

Embora o grande número de disputas com apenas dois candidatos seja um forte indício de coordenação estratégica entre as elites políticas, para verificarmos se houve voto estratégico, devemos considerar apenas aquelas eleições onde entraram mais de dois candidatos. ${ }^{9}$ O Gráfico 2 mostra a razão entre os votos do segundo candidato derrotado $(\mathrm{S})$ e o primeiro candidato derrotado $(\mathrm{F})$ para cada eleição.

Esse gráfico aponta uma grande concentração de casos próximos a 0 (zero), o que significa que há equilíbrio duvergeriano, isto é, na maior parte das eleições os eleitores concentraram seus votos nos candidatos mais viáveis. Em 50\% dos casos, a proporção de votos do segundo perdedor para o primeiro perdedor foi menor que $31 \%$, isto é, o terceiro colocado teve no máximo um terço dos votos do segundo colocado. Em 25\% dos casos, a diferença do segundo colocado para o terceiro foi mais acachapante, com este obtendo dez vezes menos votos que aquele. Em apenas 35\% dos casos, o terceiro colocado alcançou mais da metade dos votos do segundo, e só em 10\% das vezes ele chegou a mais de $87 \%$.

O Gráfico 2 também mostra que não há indício de equilíbrio não duvergeriano, dada a uniformidade da distribuição após os 30\% de razão SF. Diferente dos resultados de Cox, essa situação se repete mesmo em distritos mais competitivos, isto é, aqueles em que, em eleição prévia, o vencedor ganhou por uma margem menor do que $20 \%$.

Embora a hipótese de que eleições majoritárias de um só turno levam à deserção do terceiro candidato pareça se confirmar com esses dados, também valem aqui as explicaçóes alternativas dadas por Cox, especialmente a que sustenta dar-se a coordenação nas elites políticas. 


\section{Gráfico 2}

Distribuição da Razão de Voto entre o Terceiro e o Segundo Colocados nas Eleiçóes Municipais de 1996 a 2012 (municípios entre 10 mil e 200 mil eleitores)

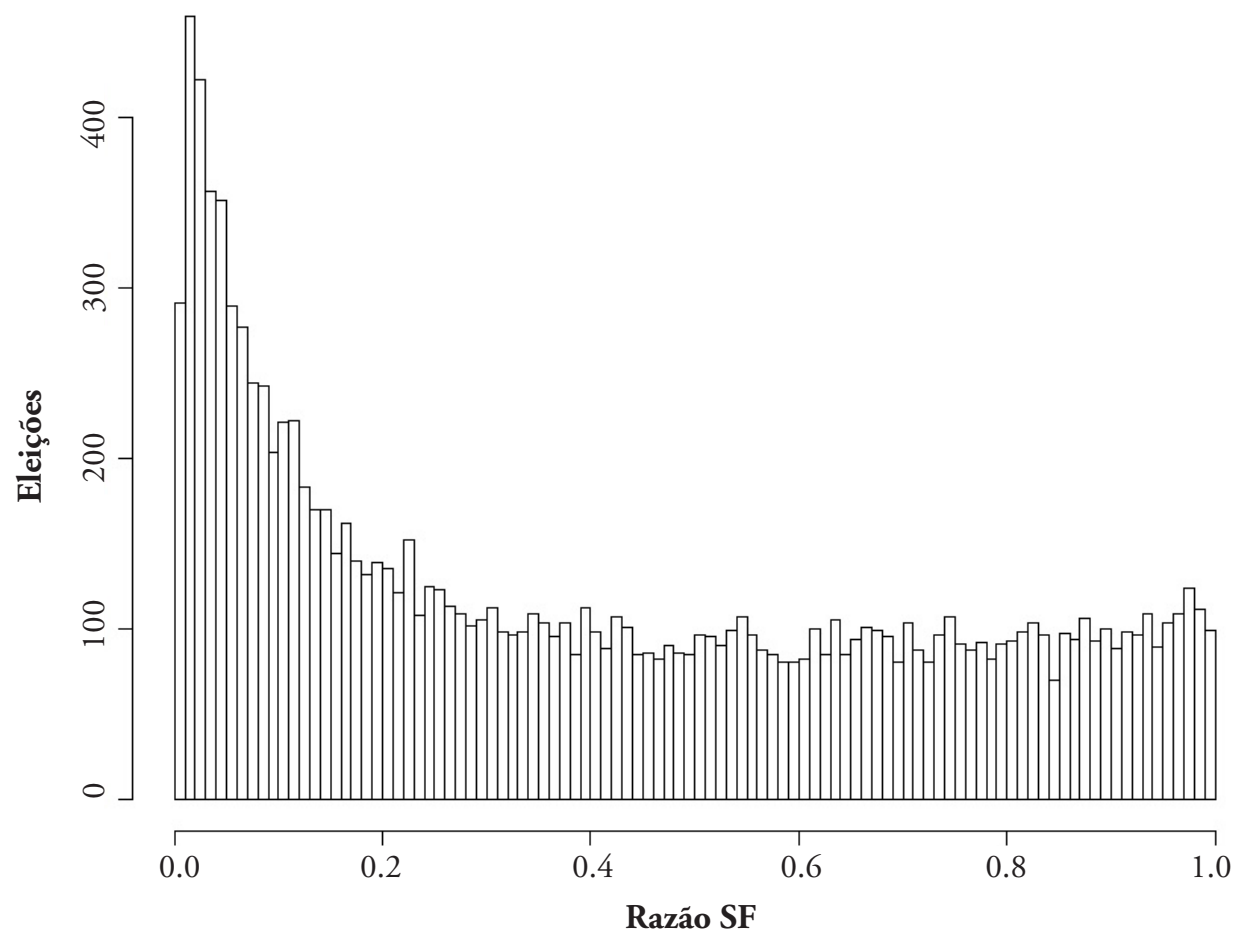

Fonte: elaboração própria a partir de dados do TSE. Disponível em http://www.tse.jus.br/eleicoes/eleicoes-anteriores/ eleicoes-anteriores, consultado em 9 set. 2015.

\section{Lei de Duverger nas eleiçóes de dois turnos para governador}

As eleições para governador de estado nos fornecem uma boa base para testar os efeitos da Lei de Duverger em sistemas majoritários de dois turnos. Entre 1990 e 2014, foram realizadas sete eleiçōes para governador nos 27 estados da federação, totalizando 189 eleiçōes. Dado que se trata de eleições majoritárias de dois turnos, esperaríamos que nas eleiçōes para governador tivéssemos, no máximo, três candidatos viáveis conforme formulação de Cox (1997). O Gráfico 3 apresenta a distribuição do número total de candidatos no período.

Vemos que, diferente do caso das eleições municipais, o número médio de candidatos ao governo de estado tem se mantido entre seis e sete, en- tre 1990 e 2014; o menor número de candidatos se deu no Tocantins em 2010 (dois), e o maior se deu em São Paulo em 2002 (quatorze). Isso está de acordo com a previsão de que, em sistemas majoritários de dois turnos, haveria mais candidatos do que em sistemas majoritários de turno único; no entanto, como o número é bem maior que três, parece, à primeira vista, que não há coordenação eleitoral entre as elites. No entanto, esses dados não permitem chegar a essa conclusão, pois não dizem nada sobre a viabilidade dos partidos que entraram na disputa e, muito menos, sobre a votação que esses partidos receberam. Para verificar se há coordenação eleitoral, precisamos analisar os dados referentes aos partidos viáveis; e, para verificar se há voto estratégico, deveremos examinar a votação dos partidos. 


\section{Gráfico 3}

Número de Candidatos nas Disputas para Governador do Estado entre 1990 a 2014

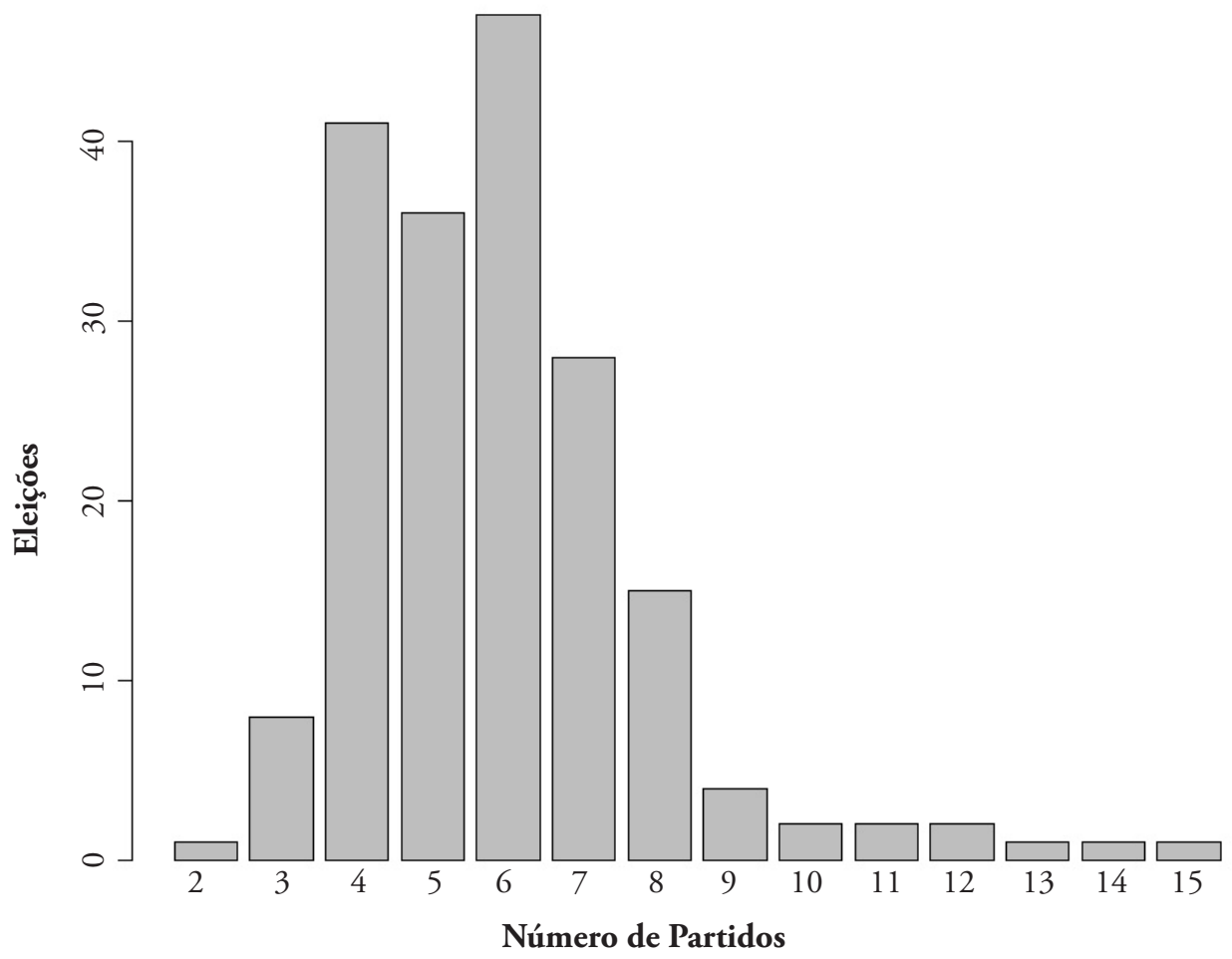

Fonte: elaboração própria a partir de dados do TSE. Disponível em http://www.tse.jus.br/eleicoes/eleicoes-anteriores/ eleicoes-anteriores, consultado em 9 set. 2015.

Começaremos pela coordenação eleitoral.

Se observarmos o número efetivo de candidatos (NEC) ao governo de estado, ${ }^{10}$ apresentados na Tabela 1 , veremos um quadro um tanto diferente daquele observado no Gráfico 3.

A Tabela 1 nos revela que quase todos os estados sempre apresentam ao redor de três candidatos quando examinamos o número efetivo. O NEC médio é 2,6, o que está de acordo com as previsões de Duverger e Cox sobre os efeitos das eleiçôes majoritárias de dois turnos. Vemos aqui que, em $84 \%$ das eleiçôes, os votos se concentram em três ou menos candidatos efetivos. Também cabe observar que, em $15 \%$ dos casos, havia menos de dois candidatos efetivos. Esses números estão bem abaixo do limite de quatro candidatos proposto por Duverger.

É interessante perceber que 54\% dos candidatos que obtiveram mais de $10 \%$ de votos perten- cem a apenas três partidos (PT, PMDB e PSDB). Sete partidos possuidores do maior número de filiados e as maiores bancadas no Congresso, no período considerado (PT, PDT, PMDB, PSDB, PTB, PFL/DEM, PDS/PP), lançaram mais de $80 \%$ dos candidatos mais votados.

Portanto, a configuração das disputas para o governo do estado envolve na média entre seis e sete candidatos, três de partidos que abocanham a maior parte dos votos e três de partidos que quase sempre ficam abaixo dos $10 \%$ de votação. Isso nos dá fortes indícios de que, no caso daqueles partidos, há coordenação por parte das elites políticas.

Para verificar se, nos casos em que essa coordenação não ocorreu, houve coordenação por parte dos eleitores, precisamos utilizar o teste de bimodalidade de Cox. O Gráfico 4 mostra a dis- 
Tabela 1

Número Efetivo de Candidatos nas Disputas para Governador do Estado entre 1990 e 2014

\begin{tabular}{|c|c|c|c|c|c|c|c|}
\hline UF & 1990 & 1994 & 1998 & 2002 & 2006 & 2010 & 2014 \\
\hline $\mathrm{AC}$ & 4,0 & 2,8 & 2,4 & 1,9 & 2,4 & 2,0 & 2,7 \\
\hline $\mathrm{AL}$ & 2,2 & 1,5 & 2,0 & 2,3 & 2,4 & 3,1 & 2,5 \\
\hline $\mathrm{AM}$ & 2,2 & 2,1 & 2,0 & 2,7 & 2,4 & 2,1 & 2,6 \\
\hline AP & 3,3 & 2,8 & 2,9 & 3,7 & 2,3 & 3,8 & 3,5 \\
\hline BA & 2,7 & 3,0 & 1,9 & 2,3 & 2,1 & 2,2 & 2,3 \\
\hline $\mathrm{CE}$ & 2,3 & 2,2 & 2,2 & 2,9 & 2,0 & 2,3 & 2,2 \\
\hline DF & 2,6 & 3,0 & 2,7 & 2,8 & 2,8 & 2,8 & 3,1 \\
\hline ES & 2,9 & 3,1 & 2,4 & 2,2 & 1,6 & 1,4 & 2,3 \\
\hline GO & 2,3 & 3,3 & 2,2 & 2,5 & 2,5 & 2,7 & 3,1 \\
\hline MA & 2,7 & 2,8 & 2,0 & 2,2 & 2,8 & 2,7 & 1,9 \\
\hline MG & 4,2 & 3,0 & 2,7 & 2,3 & 1,6 & 2,0 & 2,2 \\
\hline MS & 2,2 & 2,4 & 3,0 & 2,4 & 1,9 & 2,0 & 2,7 \\
\hline MT & 2,1 & 1,7 & 2,3 & 2,6 & 2,1 & 2,6 & 2,3 \\
\hline PA & 2,7 & 3,1 & 2,8 & 3,6 & 2,8 & 2,6 & 2,1 \\
\hline PB & 2,7 & 2,4 & 1,5 & 2,5 & 2,1 & 2,0 & 2,3 \\
\hline PE & 2,2 & 2,5 & 2,1 & 2,1 & 3,0 & 1,4 & 1,8 \\
\hline PI & 2,2 & 2,7 & 2,1 & 2,2 & 2,2 & 2,8 & 2,0 \\
\hline PR & 3,4 & 2,2 & 2,1 & 4,4 & 2,9 & 2,1 & 2,5 \\
\hline RJ & 1,8 & 3,8 & 2,8 & 2,8 & 3,7 & 2,0 & 3,8 \\
\hline RN & 2,5 & 2,3 & 2,3 & 3,5 & 2,1 & 2,4 & 2,4 \\
\hline RO & 4,1 & 2,9 & 3,5 & 5,1 & 2,6 & 2,7 & 3,4 \\
\hline RR & 3,0 & 3,1 & 2,5 & 2,1 & 2,1 & 2,3 & 2,9 \\
\hline RS & 3,4 & 2,7 & 2,3 & 3,1 & 3,8 & 2,6 & 3,1 \\
\hline SC & 2,8 & 2,9 & 2,3 & 3,1 & 2,7 & 2,6 & 2,6 \\
\hline SE & 1,6 & 2,2 & 2,9 & 3,0 & 2,1 & 2,1 & 2,2 \\
\hline SP & 2,6 & 3,3 & 4,2 & 3,3 & 2,3 & 2,6 & 2,4 \\
\hline TO & 2,5 & 2,1 & 2,0 & 2,1 & 2,1 & 2,0 & 2,2 \\
\hline
\end{tabular}

Fonte: elaboração própria a partir de dados do TSE. Disponível en http://www.tse.jus.br/eleicoes/eleicoes-anteriores/ eleicoes-anteriores, consultado em 9 set. 2015.

tribuição das razões SF nas eleições para governador em que houve segundo turno, entre 1990 e $2014 .{ }^{11}$

A razão de votos entre o quarto e o terceiro colocados fica próxima a 0 (zero) como nas eleições municipais. Em 55\% das eleições, o quarto colocado recebeu menos do que um terço dos votos do terceiro colocado, e, em $72 \%$ das vezes, recebeu menos da metade dos votos. Esses resultados são parecidos com os resultados que vimos no caso das eleiçôes de um só turno e indicam a presença de equilíbrio duvergeriano. 


\section{Gráfico 4}

Distribuição da Razão SF nas Eleiçôes para Governador em que Houve Segundo Turno, entre 1990 e 2014

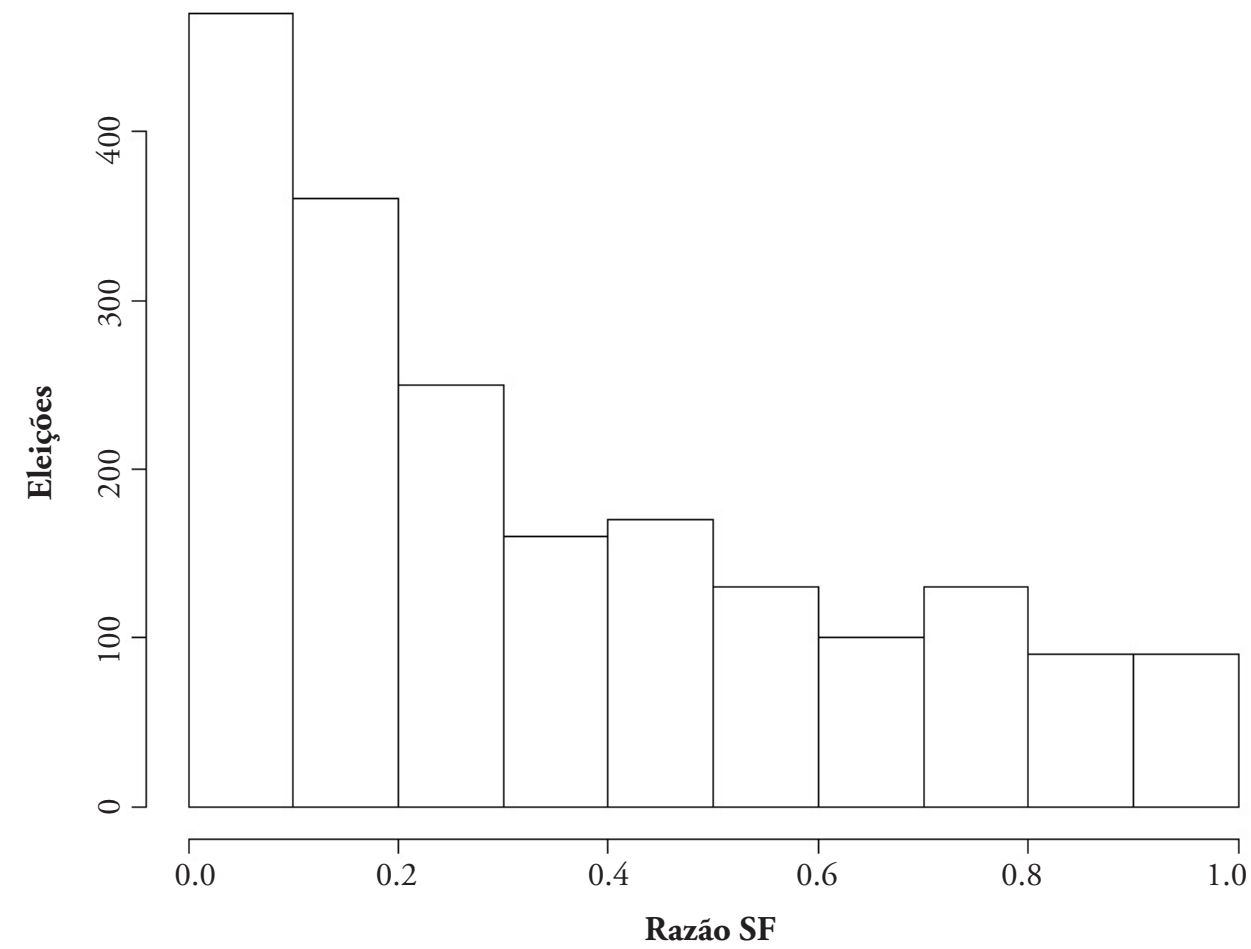

Fonte: elaboração própria a partir de dados do TSE. Disponível em http://www.tse.jus.br/eleicoes/eleicoes-anteriores/ eleicoes-anteriores, consultado em 9 set. 2015.

Tabela 2

Número de Candidatos Lançados pelos Grandes Partidos e Razão SF nas Disputas pela Presidência da República entre 1989 e 2014

\begin{tabular}{llllllll}
\hline & $\mathbf{1 9 8 9}$ & $\mathbf{1 9 9 4}$ & $\mathbf{1 9 9 8}$ & $\mathbf{2 0 0 2}$ & $\mathbf{2 0 0 6}$ & $\mathbf{2 0 1 0}$ & $\mathbf{2 0 1 4}$ \\
\hline Candidatos & 7 & 5 & 2 & 2 & 3 & 2 & 2 \\
\hline Razáo SF & 0,7 & 0,59 & 0,19 & 0,67 & 0,39 & 0,05 & 0,07 \\
\hline
\end{tabular}

Obs.: os partidos considerados grandes são: PDS/PP, PMDB, PT, PDT, PTB, PSDB, PFL/DEM. A razão SF foi calculada dividindo-se os votos do quarto colocado no primeiro turno pelos votos do terceiro colocado.

Fonte: elaboração própria a partir de dados do TSE. Disponível em http://www.tse.jus.br/eleicoes/eleicoes-anteriores/ eleicoes-anteriores, consultado em 9 set. 2015.

\section{Lei de Duverger nas eleições para presidente}

Embora o número de eleições para presidente seja pequeno para permitir qualquer conclusão, há também nelas uma tendência de coordenação por parte das elites e indícios de equilibrio duvergeriano. A Tabela 2 contém o número de candidatos em cada disputa.

$\mathrm{Na}$ eleição para presidente em 1989, não houve coordenação e todos os sete partidos grandes 
lançaram candidatos. A falta de coordenação pode ser atribuída à ausência de informação sobre as diferentes chances de cada partido. Já na segunda eleição, surge a primeira aliança entre grandes partidos (PSDB, PFL e PTB). ${ }^{12}$ A partir dessa eleição, em nenhum outro caso se apresentaram mais de três partidos grandes.

A razão $\mathrm{SF}$, declinante nas três primeiras eleiçôes, aumenta em 2002 quando novas forças oferecem candidatos, como o PPS, que lança Ciro Gomes, e o PSB, que lança Anthony Garotinho. Em 2006 , a razão $S F$ volta a se fixar bem abaixo de 0,5 , e, em 2010 e 2014, ela atinge seu valor mais baixo devido à expressiva votação recebida pela terceira colocada Marina Silva. Isso indica que, mais do que ação estratégica dos eleitores nas eleições para presidente, a redução do número de candidatos se deve à coordenação pré-eleitoral.

\section{Conclusão}

Os testes que fizemos comprovam os efeitos da Lei de Duverger tanto em eleiçóes majoritárias de um turno como em eleições majoritárias de dois turnos. Vimos que, nessas eleiçôes, ocorre o equilíbrio duvergeriano e que o candidato na $\mathrm{M}+2^{\mathrm{a}}$ posição tem, em geral, bem menos votos do que o candidato na $\mathrm{M}+1^{\text {a }}$ posição, o que indica voto estratégico.

Também chama a atenção a prevalência da coordenação pré-eleitoral. O número de candidatos lançados pelos grandes partidos em uma mesma eleição nas disputas para prefeito, governador e até mesmo presidente se iguala ao limite $\mathrm{M}+1$ na maior parte das vezes, não dando oportunidade para a ocorrência do voto estratégico.

Isso estaria de acordo com as constataçóes de Cox que, analisando o caso japonês, sugere que esses resultados se devem mais à ação das elites, que fariam um apelo para que o eleitor não desperdiçasse o seu voto, do que à racionalidade do eleitor. Nas palavras de Cox:

Meu viés pessoal é fortemente inclinado à hipótese da coordenação por parte das elites, como nos estudos sobre o comparecimento.
Penso que o voto estratégico sobrevive, tanto na teoria quanto na prática, porque uma das coisas que as elites podem fazer para transferir votos de um candidato pior colocado para um dos líderes em competiçôes apertadas é inundar os meios de comunicação com apelos contra o "desperdício de voto" (1997, p. 98, tradução do autor).

Para Cox, assim como para Duverger e Riker, a antecipação do voto estratégico por parte das elites pode levar à decisão de se lançar ou não uma candidatura ou lista. Isso daria a racionalidade por trás da decisão de um partido em estabelecer uma coligação eleitoral.

\section{Notas}

1 Jairo Nicolau, Rogério Schmitt e Maria do Socorro Braga são alguns dos poucos autores que dão maior atenção aos efeitos da Lei de Duverger sobre o número de partidos (Nicolau e Schmitt, 1995; Braga, 2006 e 2010).

2 Nesta visão, não há centro em política; apesar de poderem existir partidos de centro, esses partidos na verdade são meros "agrupamentos artificiais da parte direita da esquerda e da parte esquerda da direita" (Duverger, 1970, p. 251).

3 Assim como em Blondel (1982), para Sartori importa os partidos relevantes, neste caso partidos capazes de constituir uma coalizão.

4 Para Riker, existiriam vários casos que invalidam a associação entre representação proporcional ou sistemas majoritários de dois turnos e multipartidarismo (o que chama de Hipótese de Duverger). Riker, neste caso, não procura adaptar a proposição de Duverger, ele simplesmente abandona a hipótese na sua forma determinística, apesar de defender "uma relação probabilística um tanto forte" entre representação proporcional e sistemas de dois turnos, por um lado, e multipartidarismo por outro.

5 O problema dessa análise é que, na busca da explicação da passagem do efeito no nível local da Lei de Duverger para o nível nacional, ela deixa de fora quase todos os países que não são da Europa Ocidental, já que, conforme o próprio Sartori, é lá basicamente que se encontram partidos de massa nacionalmente organizados. Como veremos mais à frente, a crítica de Cox 
a Sartori é que ele afirma o consequente ao colocar como condição do efeito do sistema eleitoral no nível nacional a organização dos partidos nacionalmente.

6 Agradeço aos pareceristas anônimos por chamarem minha atenção para a necessidade de se incluir a importante obra de Shugart e Carey, Presidents and assemblies: constitutional design and electoral dynamics.

7 Eleiçôes não simultâneas também podem ter efeitos contaminantes conforme o período do mandato presidencial em que as eleiçôes para o legislativo ocorrem. Eleições legislativas que ocorrem no período de "lua de mel", isto é, até um ano depois de o presidente ser eleito, levam a uma maior vantagem do partido presidencial.

8 Cox alerta para o fato de que distritos pequenos não enfrentam problemas de coordenação. Assim, iremos examinar as eleições para prefeito em municípios com mais de 10 mil habitantes. O limite superior de 200 mil habitantes é aquele a partir do qual as eleições passam a ser de dois turnos.

9 O que nos deixa com um $\mathrm{N}=7.899$.

10 Seguindo a fórmula de Laakso e Taagepera (1979), o número efetivo de candidatos foi calculado como

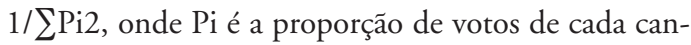
didato.

11 Excluímos as eleições em que não houve segundo turno porque, nesses casos, com o primeiro colocado obtendo mais de $50 \%$ dos votos, a votação do terceiro e quarto colocados é, em geral, muito pequena e a razão entre elas está próxima a 1, dando a ideia errônea de que os eleitores não teriam coordenado o voto. $\mathrm{Na}$ verdade, pode ter havido coordenação no sentido de se resolver a disputa no primeiro turno.

$12 \mathrm{O}$ PT se alia ao PSB que, embora não tenha mais de um milhão de filiados, tinha importância eleitoral ao ter entre seus quadros figuras como a do governador de Pernambuco Miguel Arraes.

\section{BIBLIOGRAFIA}

ALDRICH, J. H. (1995), Why parties? The origin and transformation of party politics in America. Chicago: University of Chicago Press.

AMORIN NETO, O. \& SANTOS, F. (2001), “A conexão presidencial: facçôes pró e antigoverno e disciplina partidária no Brasil”. Dados, 44 (2): 363-403.
BLONDEL, J. (1982), "Party systems and pattern of government in Western democracies", in J. Charlot, Os partidos políticos, Brasília, Editora da UnB.

BRAGA, M. do S. S. (2006), O processo partidário-eleitoral brasileiro: padróes de competição politica, 1982-2002. São Paulo, Humanitas.

. (2010), "Eleições e democracia no Brasil: a caminho de partidos e sistema partidário institucionalizados". Revista Brasileira de Ciência Politica, 4: 43-73.

CAIN, B.; FEREJOHN, J. \& FIORINA, M. (1987), The personal vote: constituency service and electoral independence. Cambridge, Londres; Harvard University Press.

COX, G. W. (1997), Making votes count: strategic coordination in the world's electoral systems. Cambridge, Cambridge University Press.

(1999), "Electoral rules and electoral coordination". Annual Review of Political Science, 2: $145-61$.

CROZIER, M. \& FRIEDBERG, E. (1977), L'acteur et le système. Paris, Éditions du Seuil.

CROZIER, M.; HUNTINGTON, S. \& WATANUKI, J. (1975), The crisis of democracy: report on the governability of democracies to the trilateral commission. Nova York, New York University Press.

DOWNS, A. (1999), Uma teoria econômica da democracia. São Paulo, Edusp.

DUVERGER, M. (1970 [1951]), Os partidos politicos. São Paulo, Zahar.

FEDDERSEN, T.; SENED, I. \& WRIGHT, S. (1990), "Sophisticated voting and candidate entry under plurality rule". American Journal of Political Science, 34.

FEY, M. (1997), "Stability and coordination in Duverger's Law: a formal model of preelection polls and strategic voting”. American Political Science Review, 91: 135-147.

FIGUEIREDO, A. C. \& LIMONGI, F. (2002), "Incentivos eleitorais, partidos e política orçamentária”. Dados, 45 (2): 303-344.

GOLDER, M. (2004), "An evolutionary approach to party system stability". Nova York, New York University [mimeo].

GREENBERG, J. \& SHEPSLE, K. (1987), "The effect of electoral rewards in multiparty com- 
petition with entry". American Political Science Review, 81: 525-538.

JONES, M. P. \& MAINWARING, S. (2003), "The nationalization of parties and party systems an empirical measure and an application to the Americas". Party Politics, 9 (2): 139-166.

KATZ, R. S. (2001), “The problem of candidate selection and models of party democracy". Political Studies, 7 (3): 277-296.

KATZ, R. S. \& MAIR, P. (1995), "Changing models of party organization and party democracy: the emergence of the cartel party". Party Politics, 1: 5-28.

KINZO, M. D. G. (1988), Oposição e autoritarismo: gênese e trajetória do MDB (1966-1979). São Paulo, Vértice/ Editora Revista dos Tribunais. (1993), Radiografia do quadro partidário brasileiro. São Paulo, Fundação Konrad-Adenauer.

KINZO, M. D. G. (2004), "Partidos, eleiçōes e democracia no Brasil Pós-1985". Revista Brasileira de Ciências Sociais, 19 (54): 23-40

KINZO, M. D. G.; BORIN, I. \& MARTINS Jr., J. P. (2003), "Padrões de competição eleitoral na disputa para a câmara paulistana 19922000". Novos Estudos Cebrap, 65: 45-56.

LAAKSO, M., \& TAAGEPERA, R. (1979). "Effective number of parties: a measure with application to West Europe". Comparative Political Studies, 12 (1): 3-27.

LIMA JR., O. B. (1983), Partidos políticos brasileiros: a experiência federal e regional: 1945/64. Rio de Janeiro, Graal.

(1999), "Partidos, eleições e poder legislativo", in S. Miceli (org.), O que ler na ciência social brasileira (1970-1995), São Paulo, Sumaré/Anpocs.

. (1997), O sistema partidário brasileiro. Rio de Janeiro, Editora FGV.

LIMONGI, F. (1999), "Institucionalização política”, in S. Miceli (org.), O que ler na ciência social brasileira (1970-1995), São Paulo, Sumaré/Anpocs.

. (2003), "Formas de governo, leis partidárias e processo decisório". $B I B, 55:$ 7-39.

LIMONGI, F. \& FIGUEIREDO, A. C. (1995), "Partidos políticos na Câmara dos Deputados: 1989-1994”. Dados, 38 (3).
MAINWARING, S. (1991), "Políticos. Partidos e sistemas eleitorais: o Brasil numa perspectiva comparada”. Novos Estudos Cebrap, 29.

. (1999), Rethinking party systems in the Third Wave of democratization: the case of Brazil. Stanford, Stanford University Press.

MAINWARING, S. \& SCULLY, T. R. (eds.). (1995), Building democratic institutions: party systems in Latin America. Stanford, Stanford University Press.

MAIR, P. (1997), Party system change, approaches and interpretations. Oxford, Clarendon Press.

MAIR, P. \& KATZ, R. (1990), How parties organize. Cambridge, Cambridge University Press.

MICHELS, R. (1962), Political parties. Glencoe, Free Press.

MOENIUS, J. \& KASUYA, Y. M. (2004), "Party linkage across districts: some party system inflation indices and their properties". Party Politics, 10 (5): 543-564.

NICOLAU, J. M. \& SCHMITT, R. (1995), “Sistema eleitoral e sistema partidário". Lua Nova, 36: 129-147.

NIEMI, R. G. \& HSIEH, J. F.-S. (2002), “Counting candidates: an alternative to the effective $N$ (with an application to the $M+1$ rule in Japan)". Party Politics, 8 (1): 75-99.

OSBORNE, M. \& SLIVINSKI, A. (1996), "A model of political competition with citizen-candidates". Quarterly Journal of Economics, 111: 65-96.

PALFREY, T. (1984), "Spatial equilibrium with entry”. Review of Economic Studies, 51: 139-156.

PANEBIANCO, A. (2005), Modelos de partidos: organização e poder nos partidos políticos. São Paulo, Martins Fontes.

PEREIRA, C. \& RENNÓ, L. (2001), "O que é que o reeleito tem? dinâmicas político-institucionais locais e nacionais nas eleições de 1998 para a Câmara dos Deputados”. Dados, 44 (2): 323-362.

PERES, P. S. (1999), O espectro da instabilidade: sistema partidário e volatilidade eleitoral no Brasil democrático. Dissertação de mestrado em ciência política. São Paulo, FFLCH/USP.

POWER, T. \& ZUCCO Jr., C. (2008), “Estimating ideology of Brazilian legislative parties, 
1990-2005: a research communication". Latin American Research Review, 44 (1): 218-246.

RIKER, W. H. (1986), “Duverger's Law revisited”, in B. Gofman e A. Lijphart, Electoral laws and their political consequences, Nova York, Aghaton Press.

RODRIGUES, L. M. (2002), Partidos ideologia e composição social: um estudo das bancadas partidárias na câmara dos deputados. São Paulo, Edusp.

ROKKAN, S. (1997), "The growth and structuring of mass politics in smaller European democracies", in P. Mair, Party system change, approaches and interpretations, Oxford, Clarendon Press.

SAMUELS, D. (1997), "Determinantes do voto partidário em sistemas eleitorais centrados no candidato: evidências sobre o Brasil”. Dados, 40 (3). Disponível em http://www.scielo.br/ scielo.php?script $=$ sci_arttext $\&$ pid $=$ S0011$-52581997000300008 \& \operatorname{lng}=$ en $\&$ tlng $=$ pt. 10.1590/S0011-52581997000300008, consultado em 8 set. 2015 .

SANTOS, A. M. (2001), "Sedimentação de lealdades partidárias no brasil: tendências e descompassos”. Revista Brasileira de Ciências Sociais, 16 (45): 69-84.

SARTORI, G. (1982), Partidos e sistemas partidários. Tradução de Waltensir Dutra, ed. rev. ampl. Rio de Janeiro/Brasília, Zahar/UnB.

. (1986), "The influence of electoral systems: faulty laws or faulty method?", in B. Gofman e A. Lijphart, Electoral laws and their political consequences, Nova York, Aghaton Press.

SCHATSHNEIDER, E. E. (1942), Party government: American government in action. Nova York, Farrar and Rinehart.

SCHMITT, R.; CARNEIRO, L. P. \& KUSCHNIR, K. (1999), "Estratégias de campanha no horário gratuito de propaganda eleitoral em eleiçôes proporcionais". Dados, 42 (2): 277-297.

SEILER, D.-L. (2000), Os partidos políticos. Brasília/ São Paulo: Editora da UnB/Imprensa Oficial.

SHUGART, M. S. \& CAREY, J. M. (1992), Presidents and assemblies: constitutional design and electoral dynamics. Cambridge, Cambridge University Press.
SORES, G. A. D. (2001), A democracia interrompida. Rio de Janeiro, Editora FGV.

SOUZA, M. do C. C. de. (1976), Estado e partidos políticos no Brasil (1930 a 1964). São Paulo, Alfa-Ômega.

TSEBELIS, G. (1998), Jogos ocultos. São Paulo, Edusp.

WEBER, S. (1992), "On hierarchical spatial competition". The Review of Economic Studies, 59: 407-425.

. (1998), "Entry deterrence in electoral spatial competition". Social Choice and Welfare, 15: 31-56. 


\section{VOTO ESTRATÉGICO E COORDENAÇÃO ELEITORAL: TESTANDO A LEI DE DUVERGER NO BRASIL}

\section{Fernando Guarnieri}

Palavras-chave: Lei de Duverger; Partidos; Coordenação eleitoral; Voto estratégico; Eleições.

Em 1951 Maurice Duverger propôs que o número de partidos em um sistema partidário era uma função dos efeitos "mecânicos" e "psicológicos" das leis eleitorais que regiam aquele sistema. Mais especificamente, escrutínios majoritários de turno único levariam ao bipartidarismo e escrutínios proporcionais levariam à multiplicação de partidos. Durante mais de 60 anos as proposições de Duverger foram criticadas, estendidas e testadas por inúmeros pesquisadores em diversos países. No entanto, surpreendentemente, no Brasil este debate teve pequena repercussão, sobretudo no que tange às eleiçôes majoritárias. Neste artigo procuro preencher essa lacuna utilizando testes que permitem identificar os efeitos da Lei de Duverger nas eleições majoritárias brasileiras e o quanto esses efeitos dependem da ação estratégica dos eleitores vis-à-vis as estratégias das elites partidárias.

\section{STRATEGIC VOTE AND ELECTORAL COORDINATION: TESTING DUVERGER'S LAW IN BRAZIL}

\author{
Fernando Guarnieri
}

Keywords: Duverger's Law; Political parties; Electoral coordination; Strategic voting; Elections.

Maurice Duverger proposed, in 1951, that the number of parties in a party system is a function of "mechanical" and "psychological" effects of the electoral laws governing such system. More specifically, majoritarian ballots of a single round would tend to lead to a two-party system, and proportional ballots to a multiplication of parties. For over 60 years, the propositions of Duverger were criticized, extended, and tested by numerous researchers in several countries. Surprisingly, however, this debate had little impact in Brazil, especially with respect to majoritarian elections. In this article, the author essays to fill such gap, using tests intended to identify the effects of Duverger's Law in Brazilian majoritarian elections, discussing how these effects depend on the voter's strategic action vis-à-vis the strategies of the party elites.

\section{VOTE STRATÉGIQUE ET COORDINATION ÉLECTORALE: TEST DE LA LOI DE DUVERGER AU BRÉSIL}

Fernando Guarnieri

Mots-clés: Loi de Duverger; Partis; Coordination électorale; Vote stratégique; Élections.

En 1951, Maurice Duverger affirmait que le nombre de partis dans un système partidaire était une fonction des effets "mécaniques" et "psychologiques" des lois électorales qui régissaient ce système; plus spécifiquement, que les scrutins majoritaires à un tour favorisent le système bipartite et les scrutins poportionnels un système de partis multiples. Pendant plus de soixante ans, les propositions de Duverger ont été critiquées, élargies et testées par de nombreux chercheurs dans différents pays. Au Brésil, ce débat a au contraire eu peu de répercussion, notamment en ce qui concerne les élections majoritaires. Le présent travail propose de combler cette lacune en utilisant des tests qui permettent d'identifier les effets de la Loi de Duverger sur les élections majoritaires brésiliennes et de voir combien ces effets dépendent de l'action stratégique des électeurs par rapport aux stratégies des élites partidaires. 